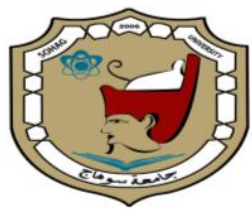

Sohag University

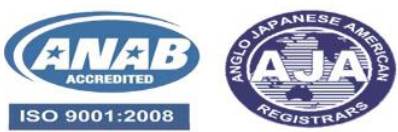

Sohag Medical Journal

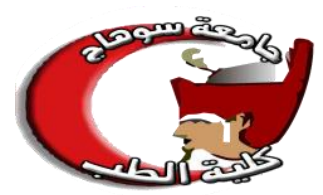

Faculty of Medicine

\title{
Comparative study between the effect of aspartame and stevia on the Purkinje cells of the cerebellar cortex of albino rats. (electron microscopic study)
}

\author{
Asmaa S. Bassit, Zahea Mohamed Esmail ${ }^{1}$, Alshimaa H. Abdelall ${ }^{2}$, Asmaa \\ M. Khalaf, Hasnaa.Ali ${ }^{3}$ \\ Department of Human Anatomy \& embryology ${ }^{1}$ biochemistry department ${ }^{2}$, department \\ of forensic medicine and clinical toxicology ${ }^{3}$, Faculty of Medicine, Sohag University
}

\begin{abstract}
:
Introduction: use of sweetener natural or artificial is widely used and appeared to harm the structure of the cerebellar cortex

Aim of the work: compare the effect of aspartame and stevia on the Purkinje cells of the cerebellar cortex of albino rats.

Material and methods: A total of 30 adult male albino rats were used animals were divided into

Group I (Control): received distilled water, Group II (ASP treated): which received aspartame (ASP), which is given at a daily dose of $250 \mathrm{mg} / \mathrm{kg}$ dissolved in distilled water for 4 weeks.

Group III (stevia treated): This received Stevia at a daily dose of $250 \mathrm{mg} / \mathrm{kg}$ given orally by intragastric tube for 4 weeks. The rats' offspring from each of the groups were randomly selected, sacrificed then their skulls were opened, and their cerebellar tissues were taken for transmission electron microscope study.

Result: aspartame affected the Purkinje cells where it becomes a shrunken loss of its piriform appearance also in the stevia-treated group, the Purkinje cells lost their piriform shape with ill define cytoplasm and nuclei while Some Purkinje cells appeared normal. Conclusion: Sativoside and aspartame appeared to harm the structure of the Purkinje cells of the cerebellar cortex.
\end{abstract}

Key word: cerebellum, purkinje, aspartame, stevia

\section{Introduction:}

The cerebellum is formed of two hemispheres attached by the vermis, a narrow midline area; it consists of white matter and grey matter located on the surface of the cerebellum and tightly folded, forming the cerebellar cortex. ${ }^{[1]}$

Its functions are to coordinate sensory to motor areas of the brain, and to coordinate movement. It provides corrections to the movement and is important in motor learning and reflex modification. [2]

The cerebellar layer has a different arrangement compared to another part of the central nervous system where Grey matter forms the cortex following all its fissures, while white matter forms the core. Internal masses of grey matter also exist to form deep cerebellar nuclei. ${ }^{[1]}$ 
Aspartame (L-aspartyl-L-phenylalanine methyl ester), a low-calorie, is sweeter about 180 times than normal sugar and is used in a lot of foods and beverages in the market, it is used in diabetic individuals and the weight loss regime. [3] Many researchers suggested neurological and behavioral adverse effects due to aspartame's metabolic components (phenylalanine, aspartic acid (aspartate), and methanol $\}$ which are produced during its breakdown. ${ }^{[4]}$ Phenylalanine passes the blood-brain barrier and leads to severe changes in the production of very important neurotransmitters. ${ }^{[4]}$

Stevia, nature's sweetener belongs to the Asteraceae group, stevia is also known as sweet leaf, honey leaf, sweet herb. ${ }^{[5]}$

Stevia is characterized by the presence of glycosides: Rebaudioside A, Rebaudioside C, stevioside, and glucoside in its leaf tissue, stevioside, a white crystalline compound isolated from stevia are 100 to 300 times sweeter than table sugar. ${ }^{[6]}$

Stevioside harms the structure of the cerebellar cortex of the albino rat where it causes a change in the Purkinje and granular cells and empty neuropils around the Purkinje cells. ${ }^{[7]}$

\section{Aim of the work:}

Studying the role of aspartame and stevia in the Purkinje cells of the cerebellar cortex of albino rats by using the electron microscope.

\section{Material and methods:}

A total of 30 adult male albino rats their weight range from 200-250g were use$\mathrm{d}$, the animals were brought from the animal house of the Assiut faculty of medicine, they were reared under the standard conditions of feeding, light-dark ratio, and temperature, in Sohag faculty of medicine animal house.
The animals were divided according to experimental study design into three groups with ten animals in each: Group I (Control Group): received distilled water.

Group II (ASP Group): received aspartame (ASP), which is given at a daily dose of $250 \mathrm{mg} / \mathrm{kg}$ liquefied in distilled water and given orally to the animals by gastric tube for 4 weeks, according to. ${ }^{[8]}$

Aspartame tablets, each one containing $20 \mathrm{mg}$, were obtained from Al-America Pharma Company

Group III (stevia Group): which taken Stevia obtained from spice dealer is given at a daily dose of $250 \mathrm{mg} / \mathrm{kg}$ given orally by gastric tube for 4 weeks.

The preparation of the extract by boiling $25 \mathrm{~g}$ of stevia leaf powder in $500 \mathrm{ml}$ water for one and a half hours till reduced to $150 \mathrm{ml}$. according to. ${ }^{[9]}$

\section{Methods:}

The rat's offspring from each group were randomly selected, sacrificed by intramuscular IM injection of a mixture of Ketamine (90 mg/kg body weight) and Xylazine $(10 \mathrm{mg} / \mathrm{kg}$ body weight) then their skulls were opened, and their cerebellar tissues were taken for transmission electron microscope study. Ultrastructural studies of the Purkinje cells of the cerebellar cortex were prepared for ultrathin sections stained with uranyl acetate, lead citrate, examined, and photographed by Jeol-JEM-100 CXII electron microscopy.

\section{Morphometric and statistical analysis}

Its animal research study in which we estimated the diameter of Purkinje cells nuclei was done by using (digitizer version 3.7.2005-2010) Medical software in the anatomy department at Sohag University. Statistical analysis of the data using spss software version 16. a variable 
was interpreted by (mean \pm standard deviation of the mean) independent t-test to compare the mean of the variable between different groups. Finally, the significance was noticed according to the level of significance ( $\mathrm{P}$-value)

\section{Results:}

\section{1-In control group:}

The Purkinje cells appeared large, having a piriform "flask" shape.

The nuclei appeared relatively large and nearly filling the cell bodies. They were vesicular and contain few chromatin granules mostly peripheral in position. Most nuclei contained one or more dark well distinct nucleoli. (figure1).

It has a large cell with a euchromatic nucleus with prominent nucleolus surrounded by a thin rim of cytoplasm. Mitochondria appeared with intact crystals, free ribosome, and rough endoplasmic retinaculum were observed. (figure2).

\section{2-Aspartame treated group:}

Purkinje cells appeared shrunken losing their piriform shape with ill-defined cytoplasm and some cells appeared deeply stained and also an area of degenerated cell appeared (figure3).

The nucleus appeared large with less condensed chromatin. The cytoplasm contained many inclusion bodies, there were dilated Rough endoplasmic retinaculum (RER) and scattered destructed mitochondria. (figure4)

Another cell appeared shrunken with electron-dense nuclei, ill define nuclear membrane and cell organelles. (figure5).

\section{3-Stevia treated group:}

Purkinje cells lost their piriform shape with ill define cytoplasm and ill-defined nuclei. Some Purkinje cells appeared normal with flask shape other were shrunken deeply stained with pyknotic nuclei. (figure6).
The cell had an eccentric nucleus with condensed chromatin and prominent nucleolus, the cytoplasm contains scattered mitochondria with destructed cristae, rough endoplasmic retinaculum.

Other cells were severely shrunken with electron-dense nuclei and non-defined nuclear membrane and cell organelles. (figure7).

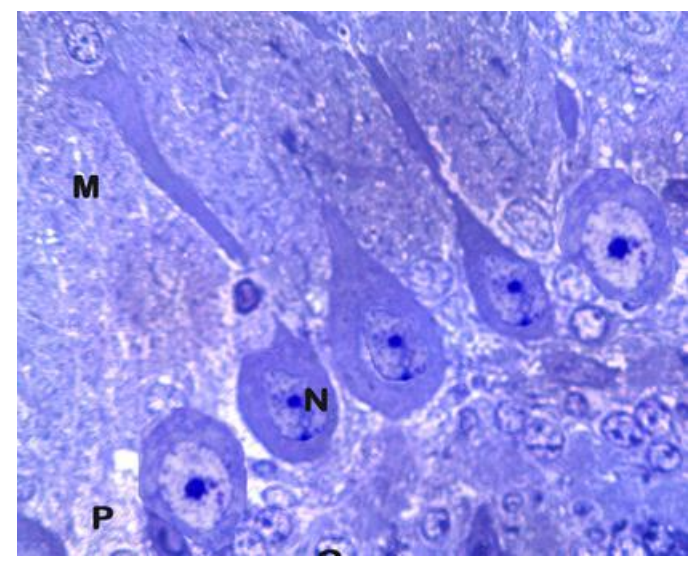

Figure (1): A semithin section of the cerebellar cortex of the control group showing molecular layer (M). Purkinje cells (p) appear with a large central vesicular nucleus(N).

Toluidine blue, $\times 1000$.

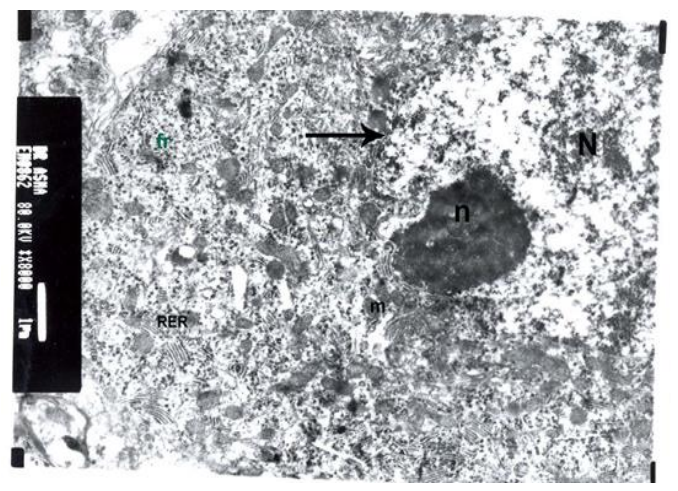

Figure (2): An electron micrograph of control group showing Purkinje cell with nucleus (N) has well-defined nuclear border(arrow) with eccentric nucleolus (n), the cytoplasm with well-defined organelles and Mitochondria (m) with preserved cristae, Rough endoplasmic reticulum (RER), and free ribosomes

$\mathbf{x} 8000$ 


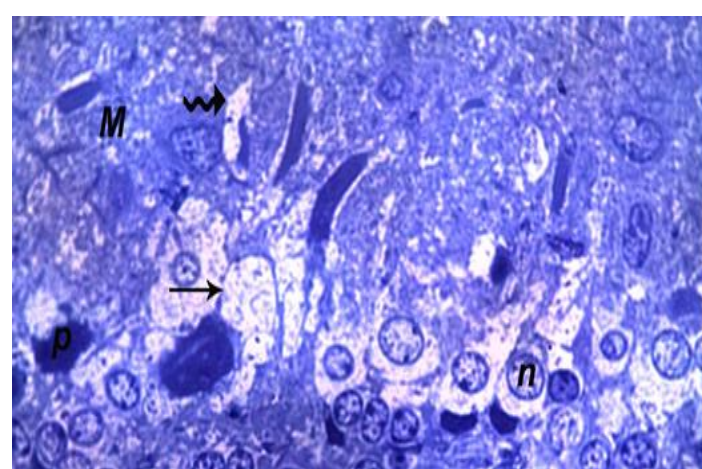

Figure (3): A semi-thin section of the cerebellar cortex of the aspartame treated group shows a molecular layer(M) with empty spaces (irregular row). Purkinje cells(p) appear small than control with ill define cytoplasm small size condensed nucleus (n), there is a cell with loss of nucleus (arrow) area of degenerated cell also appeared as empty spaces. Toluidine blue $\times 1000$.

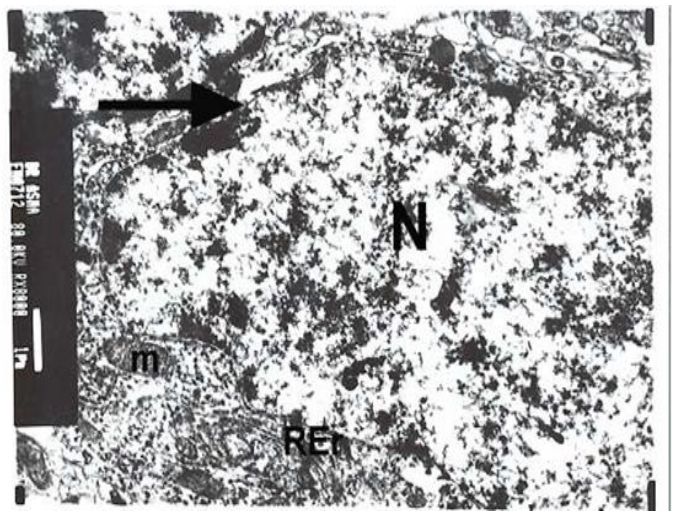

Figure (4): An electron micrograph of aspartame treated group showing a Purkinje cell with ill-defined nucleus(N) less condensed chromatin with the irregular thin cell membrane (long arrow), surrounded by cytoplasm contain mitochondria with destructed cristae (m). Dilated rough endoplasmic retinaculum (REr) x8000.

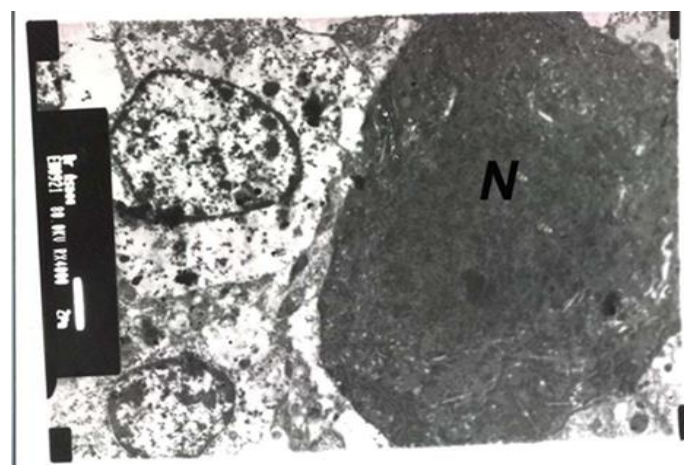

Figure (5): An electron micrograph of aspartame treated group showing shrunken Purkinje cell with Electron dense nucleus(N) with ill define nuclear envelope and cell organelles. $\mathbf{x 4 0 0 0}$

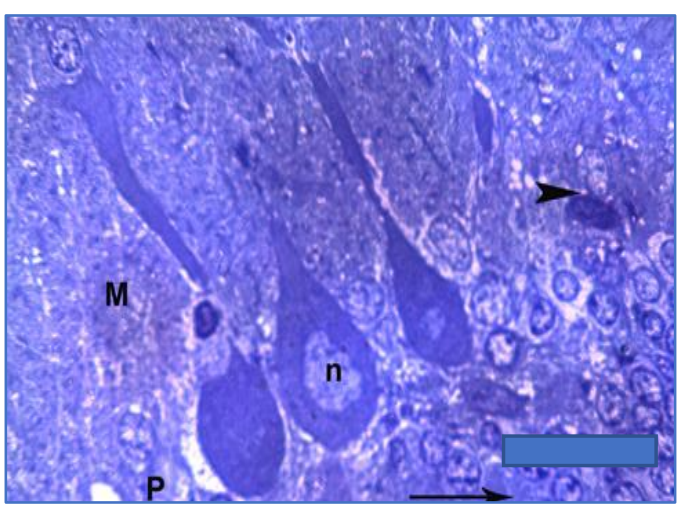

Figure (6): A semithin section of the cerebellar cortex of stevia treated group showing no apparent change in molecular cell layer (M), Purkinje cells (p) with an ill-defined nucleus and deeply stained cytoplasm, area of shrunken cell with deeply stained pyknotic nuclei (arrowhead), also, there normal Purkinje cell appears with a well-defined nucleus (n).

\section{Toluidine blue x1000}

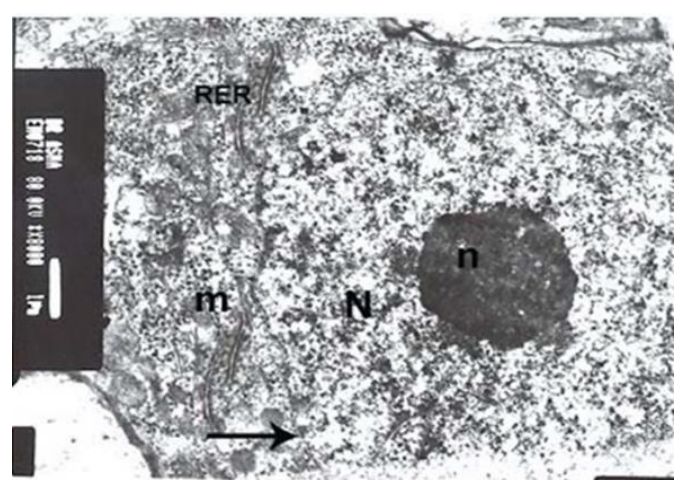

Figure (7): An electron micrograph of stevia treated group showing Purkinje cells with large, indented nuclei(N), prominent nucleolus (n), and condensed chromatin surrounded by the irregular ill-defined nuclear envelope(arrow). the cytoplasm contains scattered mitochondria (M) with destructed cristae $(\mathbf{m})$, rough endoplasmic retinaculum (RER). organelles. $\times \mathbf{4 0 0 0 .}$ 


\section{Morphometric and statistical study:}

- The mean value of Purkinje cell nuclear diameter in the aspartame treated group was $(116 \mu \mathrm{m})$. significantly decrease $\quad(\mathrm{P} \leq 0.001)$ compared to the control group.

Table (1): showing the mean value \pm standard deviation of the Purkinje cell diameter in both control and treated groups.

\begin{tabular}{|l|l|l|l|}
\hline & $\begin{array}{l}\text { Control } \\
\text { group }\end{array}$ & Aspartame treated group & $\begin{array}{l}\text { Stevia } \\
\text { group }\end{array}$ \\
\hline Purkinje cell diameter & $170 \pm 35.4$ & $116 \pm 42(* * *)$ & $99 \pm 20.9(* * *)$ \\
\hline
\end{tabular}

Ns $\rightarrow$ (non-significant)

$\mathrm{P} \leq 0.05(*) \rightarrow$ Significant difference.

$\mathrm{P} \leq 0.01(* *) \rightarrow$ High significant difference.

$\mathrm{P} \leq 0.001(* * *) \rightarrow$ Very high significant difference

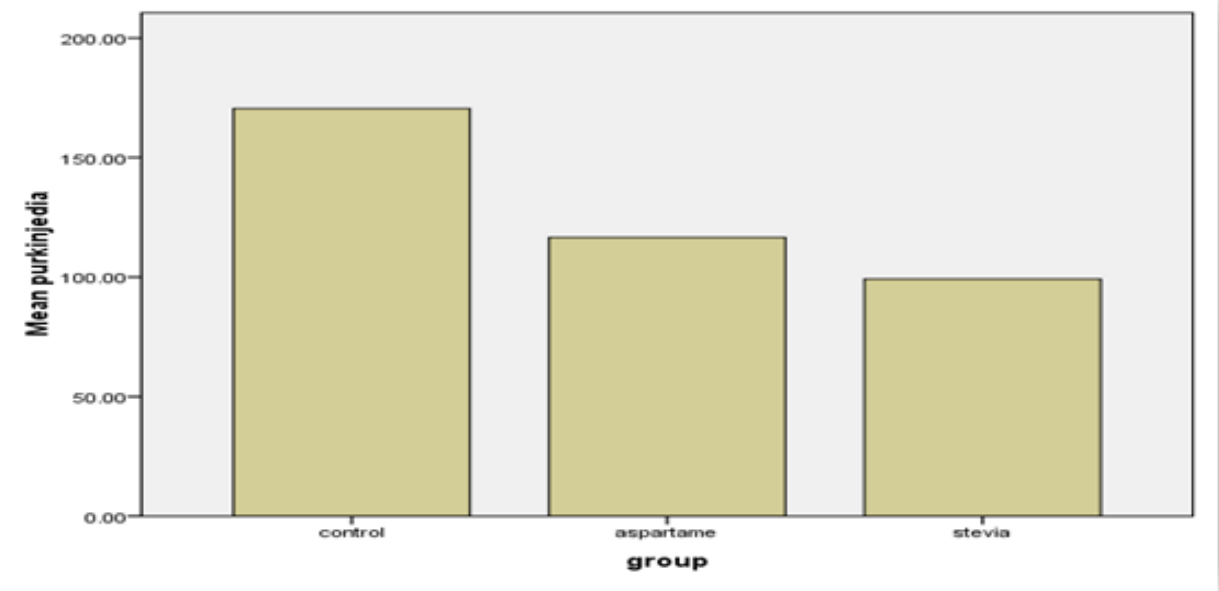

Histogram (1): showing the diameter of Purkinje cells of the control and treated groups.

\section{Discussion:}

The simple construction of the cerebellar cortex provides favorable conditions for studying neurogenesis and morphogennesis. Its neurons as Purkinje cells and granule cells are the most important targets in the cerebellum for toxic substances. ${ }^{[10]}$

Aspartame (ASP) is the most frequently used sweetener. Once entering the body, ASP hydrolyzed to form phenylalanine, aspartic acid, and methanol. It produces
- The mean value of Purkinje cell nuclear diameter in the stevia-treated group was $(99,11 \mu \mathrm{m})$. significantly decrease $(\mathrm{P} \leq 0.001)$ compared to the control group. 
m contained many inclusion bodies, dilated rough endoplasmic reticulum, and destructed mitochondria.

These results were in acceptance with Abdul-Hamid and Gallery ${ }^{[12]}$ that showed in aspartame treated animals that Purkinje cells appeared shrunken small size with deeply stained cytoplasm.

Eluwa ${ }^{[13]}$ reported that diet soda which contains aspartame caused shrunken and degenerated Purkinje cells of the cerebellum and hypertrophy of the molecular layer.

Also, A beer ${ }^{[14]}$ found in aspartame treated animals that Purkinje cells appeared with small nuclei and condensed chromatin. Some mitochondria appeared with destructed cristae. Granular cells appeared small in size.

In the present study cerebellum of stevia-treated animals revealed that Some Purkinje cells appeared normal with flask shape other Purkinje cells lost their piriform shape with ill define cytoplasm and ill-defined nuclei with shrunken deeply stained pyknotic nuclei, and scatered mitochondria with destructed cristae, rough endoplasmic reticulum.

This result agrees with Nashwa Mohamed [7] who found that in the stevia treated group, Purkinje cells had iregular cell bodies associated with electron-dense cytoplasm, and nuclei were observed. Some mitochondria had destroyed the cristae.

Also, Heba $\mathbf{M}^{\left[{ }^{[15}\right]}$ stated that fluoride treatment can affect the cerebellar cortex leading to shrunken Purkinje cells, increased the folding of the nuclear envelope, mitochondrial alterations, dilated rough endoplasmic reticulum cisternae, and clusters of vesicles near the Golgi bodies were observed.

\section{Conclusion:}

Stevia and aspartame appeared to harm the structure of the Purkinje cells of the cerebellar cortex, where Purkinje cells appeared shrunken with loss of their piriform shape, and some cells were destructed.

\section{References:}

1. Tortora $G \quad J$ and Nielson MT. Principles of human anatomy 11th edition; chapter 19 the brain and the cranial nerves; 2009.pp 612-658.

2. Nolte J. The Human Brain - An Introduction to Its Functional Anatomy; Mosby, Inc (St. Louis, Missouri) Paperback, 1993, p. 348.

3. Shapiro RB. Statement for the labor and human resources committee, US Senate (Washington, DC, Government Printing Office) the brain European Journal of Clinical Nutrition 2008, 62, 451-462;

4. Humphries P, Pretorius E, and Naudé H. Direct and indirect cellular effects of aspartame on the brain, Eur, J, Clin, Nutr 2008;62(4):451-462.

5. Sharma N, Kaushal N, Chawla A, Mohan M, Sethi A, Sharma Y. Stevia rebaudiana-A review. Agrobios Newslett 2006; 5(7):46-48.

6. Yasukawa K, Kitanaka S, Seo S.Inhibitory effect of stevioside on tumor promotion by 12-0-TCA in two stages carcinogenesis in mouse skin. Biol PharmaBull 2002; 25: 14881499.

7. Nashwa A Mohamed. Chronic effect of aspartame versus stevioside on the cerebellar cortex of the adult albino rat: a histological and immunohistochemical study, The Egyptian Journal of Histology 2013; 36:213-232.

8. Vences-Mejía A, Labra-Ruíz N, Hernández-Martínez N, DoradoGonzález V, Gómez-Garduño J, PérezLópez I, et al. The effect of aspartame on rat brain xenobioticmetabolizing 
enzymes;HumExpToxicol 2006

Aug;25 (8):453-9. .

9. Sumon M H, Mostofa M, Jahan M S, Kayesh1 MEH and Haque1 M A. comparative efficacy of powdered form of stevia (stevia rebaudiana Bertoni) leaves and glimepiride in induced diabetic rats Bangl. J. Vet 2008Med; 6, p: 211-215.

10. Fonnum F, Lock EA. Cerebellum as a target for toxic substances. Toxicol Lett. 2000 Mar 15;112113:9-16.

11. Brusick DJ. A critical review of the genetic toxicity of steviol and steviol glycosides. Food Chem Toxicol. 2008 Jul;46 Suppl 7: S83-91.

12. Abdul-Hamid M1\&Gallaly SR. Ameliorative effect of Pimpinella anisum oil on immunohistochemical and ultrastructural changes of cerebellum of albino rats induced by aspartame. Ultrastruct Pathol 2014 May;38(3):224-36.

13. Eluwa MA, Inyangmme II, Akpantah AO, Ekanem TB, Ekong MB, Asuquo OR, et al. comparative study of the effect of diet and soda carbonated drinks on the histology of the cerebellum of adult female albino Wistar rats. Afr Health Sci. 2013 Sep;13(3):541-5.

14. Abeer A. Abd El-Samad. Light and Electron Microscopic Study on the Effect of Aspartame on the cerebellar Cortex of Male Albino Rat Egypt. J. Histol 2010; Vol. 33, No. 3: $419-430$.

15. Heba M. Saad El-Dien, Dalia A. El Gamal, Heba A. Mubarak, and Samira M. Saleh. Effect of Fluoride on Rat Cerebellar Cortex: Light and Electron Microscopic studies Egypt. J. Histol. 2010.Vol. 33, No. 2, June: 245-256. 